\title{
Penerapan Teknologi Pembakaran Batu Kapur Dengan Tungku Tegak SiSTEM BERKALA MENGgUNAKAN BAHAN BAKAR BATUBARA - KAYU
}

\author{
Linda Pulungan ${ }^{1 *}$, Siti Sunendiari ${ }^{2)}$, Yunus Ashari ${ }^{1)}$, Zaenal ${ }^{1)}$ \\ 1.2) Universitas Islam Bandung, Bandung, Indonesia. \\ email: *linda.lindahas@unisba.ac.id
}

\begin{abstract}
Padalarang is located in Cipatat District, Bandung Regency, known as the largest limestone producing area in Indonesia. Limestone mining activities and processing industries are very potential, starting from the marble stone industry, quicklime industry $(\mathrm{CaO})$ to calcium oxide industry $\left(\mathrm{Ca}(\mathrm{OH})_{2}\right)$. One product of limestone processing is calcium lime $(\mathrm{CaO})$, the result of the calcination process of limestone, on burning limestone that requires large heat. The combustion activities in the majority of the limestone industrial using traditional technology use upright stoves with an open burning combustion system. The fuel used is textile industry waste, shoe industry plus wood waste. The pilot activity of the application of upright furnace limestone combustion technology is a periodically upright combustion system with fuels that have high calorific value, coal and wood. The purpose of mixing this fuel is to use available wood and coal having high calories. This activity also provides education about limestone combustion systems using coal and wood. The application of limestone combustion technology using mixed fuels of coal and wood produces quality limestone with dry conditions with an average combustion temperature of $93.75^{\circ} \mathrm{C}$ and compared to using wood fuels and industrial waste produces limestone in dry moist conditions $86.33^{\circ} \mathrm{C}$.
\end{abstract}

Keywords: Limestone, Calcination, Coal, Combustion Temperatur

\begin{abstract}
Abstrak. Kegiatan pertambangan batu gamping di Kecamatan Cipatat Kabupaten Bandung industri pengolahannya sangat potensil, mulai dari industri batu marmer, industri kapur tohor $(\mathrm{CaO})$ hingga industri kapur padam $\left(\mathrm{Ca}(\mathrm{OH})_{2}\right)$. Produk dari pengolahan batu gamping adalah kapur tohor (CaO), hasil proses kalsinasi batu kapur. pada pembakaran batu gamping yang membutuhkan panas yang besar. Kegiatan pembakaran pada pabrik-pabrik industri kapur tohor mayoritas menggunakan teknologi tradisional menggunakan tungku tegak dengan sitem pembakaran open burning. Bahan bakar yang dipakai adalah limbah industri tekstil, limbah industri sepatu ditambah kayu. Kegiatan percontohan penerapan teknologi pembakaran batu kapur tungku tegak sistem pembakaran tegak berkala dengan bahan bakar yang mempunyai nilai kalori tinggi yaitu batubara dan kayu. Tujuan mencampur bahan bakar ini memanfaatkan kayu bahan bakar yang tersedia dan batubara mempunyai kalori tinggi. Kegiatan ini juga memberikan edukasi tentang sistem pembakaran batu kapur menggunakan batubara dan kayu. Kegiatan penerapan teknologi pembakaran batu kapur dengan menggunakan bahan bakar campuran batubara dan kayu menghasilkan batu kapur berkualitas dengan kondisi kering suhu pembakaran rata-rata $93,75^{\circ} \mathrm{C}$ dan dibandingkan dengan menggunakan bahan bakar kayu dan limbah industri menghasilkan batu kapur kondisi kering lembab suhu pembakaran $86,33^{\circ} \mathrm{C}$.
\end{abstract}

Kata kunci : Batu Gamping, Kalsinasi, Batubara, Temperatur Hasil Pembakaran 


\section{Pendahuluan}

Seiring pesatnya perkembangan ilmu pengetahuan serta pertambahan penduduk dewasa ini, kebutuhan akan batu kapur juga semakin meningkat. Batu kapur dengan beragam produk olahannya menjadi salah satu hal penting dalam proses pembangunan dan berbagai proses industri Batu kapur merupakan jenis bahan galian non logam yang menjadi bahan baku utama di dalam beberapa kepentingan, antara lain bahan bakar di PLTU, bahan baku semen, bahan keramik, bahan cat, industri pupuk, industri kaca, odol, kosmetik, penjernihan air di PDAM, dan sebagainya.

Padalarang terkenal sebagai salah satu daerah penghasil batu kapur terbesar di Indonesia. Tak heran ada banyak pertambangan batu kapur serta industri pengolahannya di daerah ini, mulai dari industri batu marmer, industri kapur tohor $(\mathrm{CaO})$ hingga industri kapur padam $(\mathrm{Ca}(\mathrm{OH}) 2)$. Peningkatan kebutuhan akan batu kapur ini menjadikan Padalarang sebagai daerah yang sibuk. Sibuk menambang dan mengolah batu kapur menjadi beragam produk. Salah satu produk dari pengolahan batu kapur adalah kapur tohor $(\mathrm{CaO})$. Kapur tohor (quicklime) merupakan hasil proses kalsinasi batu kapur. Proses kalsinasi ini membutuhkan panas yang besar. Pada kebanyakan industri kapur tohor di daerah Padalarang kebutuhan akan panas ini disuplai melalui kegiatan pembakaran (combustion). Kegiatan ini merupakan kegiatan utama pada industri kapur tohor.

Kegiatan pembakaran pada pabrik-pabrik industri kapur tohor di Padalarang salah satunya yang dilakukan di tempat Pembakaran Kapur Sinar
Sakti, mayoritas masih menggunakan teknologi tradisional. Teknologi tradisional ini menggunakan metode pembakaran open burning. Bahan bakar yang dipakai oleh pabrik adalah barangbarang limbah industri tekstil dan sepatu ditambah kayu. Bahan bakar ini tergolong dalam jenis Refuse Derived Fuel (RDF). Penggunaan bahan bakar ini menyebabkan tidak tercapainya kualitas pembakaran disebabkan panas (kalori) yang dihasilkan tidak maksimal untuk pembakaran.

Batu Gamping atau dikenal dengan batu kapur adalah salah satu mineral industri yang banyak digunakan oleh sektor industri, konstruksi dan pertanian, antara lain untuk bahan bangunan, batu bangunan, bahan penstabil jalan raya, pengapuran untuk pertanian, bahan keramik, industri kaca, industri semen, pembuatan karbid, untuk peleburan dan pemurnian baja, untuk bahan pemutih dalam industri kertas pulp dan karet, untuk pembuatan soda abu, untuk penjernih air, untuk proses pengendapan bijih logam non-ferous dan industri gula. Sumber daya mineral ini cukup besar sehingga pengembangan industri pertambangannya memiliki prospek yang baik.

Di beberapa daerah endapan batu gamping/kapur seringkali ditemukan di gua dan sungai bawah tanah. Hal ini terjadi akibat reaksi tanah. Air hujan yang mengandung $\mathrm{CO}_{3}$ dari udara maupun dari hasil pembusukan zat-zat organik di permukaan, setelah meresap ke dalam tanah dapat melarutkan batu kapur yang dilaluinya. Reaksi kimia dari proses tersebut adalah sebagai berikut:

$\mathrm{CaCO}_{3}+2 \mathrm{H}_{2} \mathrm{O}+\mathrm{H}_{2} \mathrm{O} \rightarrow \mathrm{Ca}$ $\left(\mathrm{HCO}_{3}\right)_{2}+\mathrm{CO}_{2}$

$\mathrm{Ca}\left(\mathrm{HCO}_{3}\right)_{2}$ larut dalam air, sehingga lambat laun terjadi rongga 
didalam tubuh batu kapur tersebut. Secara geologi, batu kapur erat sekali hubungannya dengan dolomit. Karena pengaruh pelindian (leaching) atau peresapan unsur magnesium dari air laut ke dalam batu kapur, maka batu kapur tersebut dapat berubah menjadi golongan dolomitan atau jadi dolomit. Kadar dolomit atau $\mathrm{MgO}$ dalam batu kapur yang berbeda akan memberikan klasifikasi yang berlainan pula pada jenis batu kapur tersebut.

Tabel 1 Pengklasifikasian Dolomit Berdasarkan Kandungannya

\begin{tabular}{|l|c|c|}
\hline Nama Batuan & $\begin{array}{c}\text { Kadar } \\
\text { Dolomit }\end{array}$ & $\begin{array}{c}\text { Kadar } \\
\text { MgO } \\
\text { (\%) }\end{array}$ \\
\hline Batu Gamping & $0-5$ & $0,1-1,1$ \\
\hline $\begin{array}{l}\text { Batu Gamping } \\
\text { bermagnesium }\end{array}$ & $5-10$ & $1,1-2,2$ \\
\hline $\begin{array}{l}\text { Batu Gamping } \\
\text { dolomitan }\end{array}$ & $10-50$ & $2,2-$ \\
\hline $\begin{array}{l}\text { Dolomit } \\
\text { berkalsium }\end{array}$ & $50-90$ & $\begin{array}{c}10,9- \\
19,7\end{array}$ \\
\hline Dolomit & $90-100$ & $\begin{array}{c}19,7- \\
21,8\end{array}$ \\
\hline
\end{tabular}

Sumber : Petti John, 1956

Proses pembuatan kapur tohor $(\mathrm{CaO})$ dari batu kapur $(\mathrm{CaCO} 3)$ merupakan proses yang simpel dan sederhana, namun perlu mengerti dan memahami dasar-dasar proses kimia terutama dalam proses kalsinasi batu kapur menjadi kapur tohor yang meliputi neraca bahan maupun neraca panas. Pada proses pembakaran terjadi produksi panas yang disebabkan oleh adanya reaksi oksidasi pada bahan bakar. Proses pembakaran tak sempurna menghasilkan panas yang lebih rendah dibanding pembakaran sempurna. Hal ini disebabkan pada pembakaran tidak sempurna rantai hidrokarbon dari bahan bakar tidak terdegradasi secara sempurna menjadi CO2. Sebagian masih ada yang berbentuk rantai panjang dan terbang bersama emisi dalam bentuk partikulat atau jelaga. Akibatnya, potensial panas yang terkandung dalam bahan bakar tidak dapat dihasilkan seluruhnya sehingga panas yang dihasilkan menjadi lebih kecil.

Proses produksi kapur tohor membutuhkan panas yang cukup. Tujuannya adalah agar terjadi pemanasan batu kapur hingga suhu dimana ia terdekomposisi menjadi kapur tohor. Hasil penelitian Andrej Senegačnik et al. (2007) menunjukkan bahwa proses kalsinasi tersebut berlangsung pada suhu $820^{\circ} \mathrm{C}$ dan $830^{\circ} \mathrm{C}$. Agar menghasilkan kapur tohor dengan reakivitas yang baik dibutuhkan temperatur optimum kalsinasi sebesar $900^{\circ} \mathrm{C}$ (Moropoulou:2001). Kebutuhan panas minimum dalam proses produksi kapur tohor adalah $1175 \mathrm{kcal} / \mathrm{kg} \mathrm{CaO}$ (Oates: 1998). Kebutuhan panas tersebut dipenuhi melalui mekanisme pembakaran. Pembakaran batu gamping biasa dilakukan dalam tungku. Jenis tungku produksi kapur tohor ada beberapa jenis, yakni tungku putar, tungku tegak dan tungku bentuk lain-lain (Beach, 2000).

Temperatur pada saat proses kalsinasi, batu gamping dipanaskan hingga mencapai $900^{\circ} \mathrm{C}$. Energi panas yang dihasilkan oleh furnace mengalir secara konduksi ke seluruh bagian permukaan batu gamping. Panas tersebut cukup untuk menguraikan batu gamping menjadi oksidanya dan gas karbon dioksida. Proses penguraian tersebut menyebabkan massa dari batu gamping berkurang. 


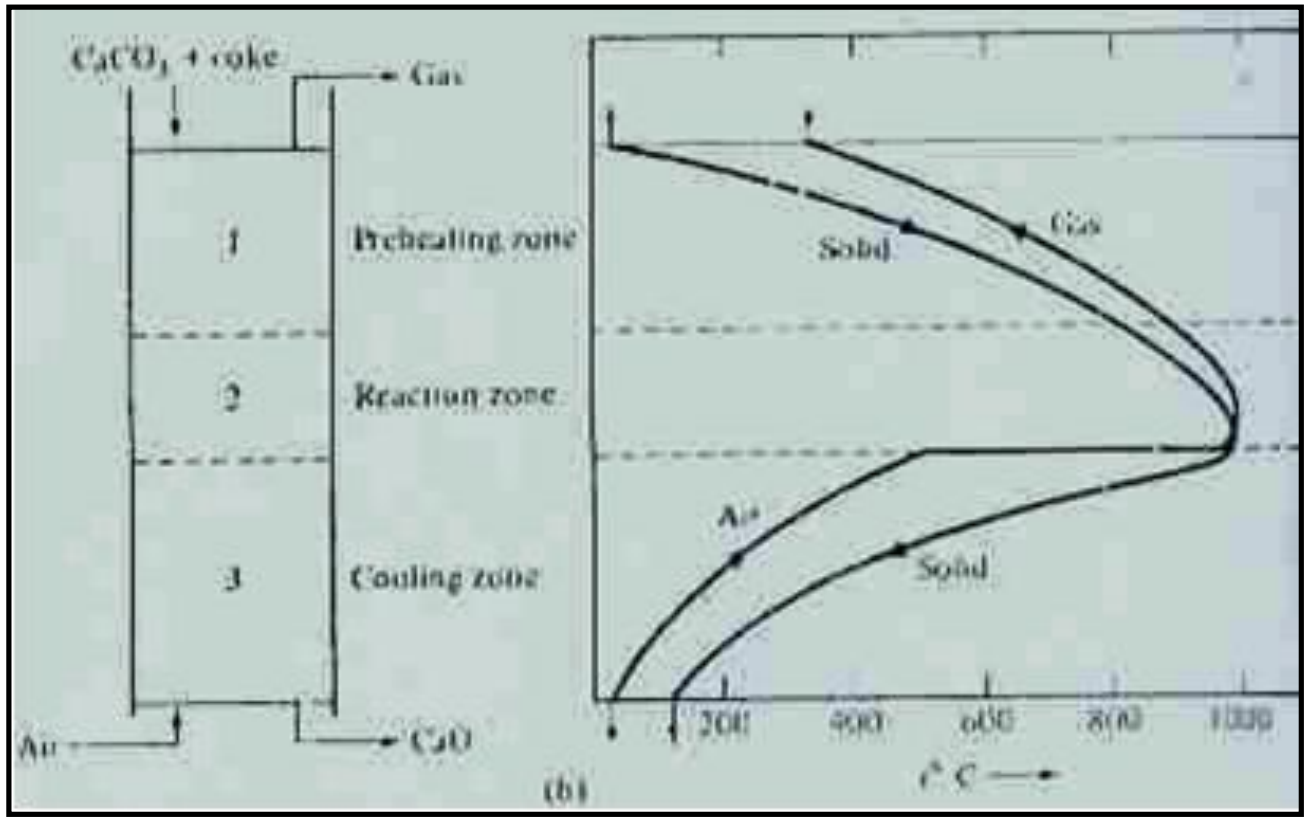

Gambar 1 Zone Kalsinasi dalam Furnace dan Temperatur

Kalsinasi Dalam furnace ada tiga zone pemanasan dalam kalsinasi :

\section{The Preheating Zone}

Batu kapur dipanaskan sampai $800^{\circ} \mathrm{C}$, belum terjadi reaksi kalsinasi.

\section{The Reaction Zone}

Batu kapur dipanaskan dengan suhu $900^{\circ} \mathrm{C}$, temperatur efektif untuk proses kalsinasi batu kapur. Dalam zone ini terjadi reaksi kalsinasi.

\section{The Cooling Zone}

Batu kapur yang dipanskan, dalam zone ini didinginkan sampai suhu $100^{\circ} \mathrm{C}$. Proses kalsinasi banyak

\section{Metodologi Penelitian}

\section{Tahap Persiapan}

Kegiatan dimulai dengan pengadaan bahan baku yang terdiri dari batu kapur yang berasal dari tambang batu kapur disekitar pabrik, bahan bakar kayu, batubara dan limbah ban bekas.. Proses penyusunan batu kapur di dalam tungku merupakan langkah penting untuk terlaksananya proses pembakaran digunakan dalam industri, seperti pada industri semen dan pembuatan serbuk nikel ferit. Panas tidak hanya bergerak kepermukaan tetapi juga berdifusi kedalam batu kapur. Laju dari kalsinasi batu kapur sangat bergantung pada bentuk dan ukuran dari butiran batu kapur serta temperatur dan lama pemanasan yang digunakan. Semakin bulat bentuk butiran maka proses pemanasan akan semakin efektif karena panas dapat berdifusi secara bebas dari segala sudut permukaan butir sehingga distribusi panas merata dan reaksi kalsinasi dapat maksimal. Semakin tinggi suhu maka waktu yang diperlukan untuk reaksi dekomposisi semakin cepat.

yang efisien dan merata ke seluruh umpan batu kapur yang akan dibakar sehingga seluruhnya terkalsinasi menjadi kapur tohor. Industri pembakaran kapur termasuk industri yang padat energi karena $50-60 \%$ biaya produksinya merupakan biaya energi. Semakin ke atas, batu kapur yang disusun semakin kecil ukurannya dan 
susunan dibuat semakin ke tengah dan akhirnya bertemu pada ketinggian $\pm 1 / 3$ tinggi umpan dari dasar tungku atau 1- 2 m. Terbentuklah sebuah rongga berbentuk setengah bola. Lubang pengapian dari luar tungku tembus ke dalam rongga ini. Karena bentuk yang demikian mengakibatkan terciptanya turbulensi yang tinggi dalam rongga pembakaran ini, setelah suhu meningkat. Kondisi ini cukup ideal untuk proses pembakaran batu bara halus. Untuk tungku berisi 10-12 ton batu kapur memerlukan 10-12 ton dalam waktu 1hari 1malam.

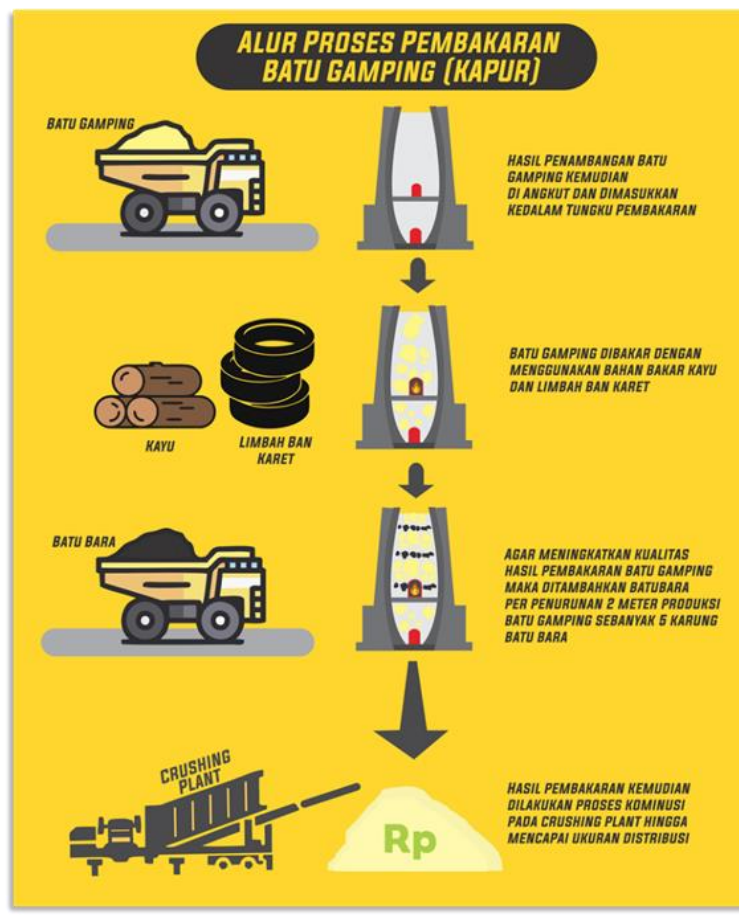

Gambar 2 Alur Proses Pembakaran Batu Kapur

\section{Tahap pembakaran}

Pembakaran dimulai dengan api kecil menggunakan kayu bakar untuk mengeringkan batu kapur. Api dapat dibesarkan setelah batu kapur hampir kering sehingga uap air tidak terlalu banyak. Banyaknya uap air akan mengganggu draft (tarikan) sehingga pembakaran kurang lancar, banyak menghasilkan jelaga yang mengganggu proses pembakaran selanjutnya.

Jika unggun batu kapur sudah hampir kering, draft sudah cukup kuat, api dapat semakin dibesarkan. Setelah api besar dan stabil, batubara halus dapat dimasukkan. Ukuran butir batu bara halus adalah 30 mesh dan cara pemasukannya adalah dengan mengalirkannya ke dalam pipa yang ditiup blower. Tahap pembakaran adalah tahap dimana batu kapur dibakar sampai menjadi kapur.

Proses

pembakaran menggunakan jenis tungku tegak (vertikal) berbentuk memanjang ke atas seperti piramida tumpul dengan dibatasi batu tahan api atau bertulang besi . Kompor pengapian terdiri dari, pertama 2 drum, drum pertama berisi air dan drum kedua berisi bahan bakar. Kedua, Pipa besi, fungsinya sebagai saluran air dan saluran bahan bakar. Ketiga, brander, merupakan alat untuk mempertemukan uap air dengan bahan bakar,

Batu bara halus masuk ke pipa peniupan dari pipa pengumpan. Pemasukan batu bara halus ke pipa pengumpan untuk kemudian ditiupkan ke dalam ruang bakar dilakukan dengan sistem pengumpan.

Turbulensi tercipta karena draft yang kuat dari unggun kapur dan udara luar masuk ke dalam rongga melalui lubang pengapian yang sempit. Kondisi ini sangat membantu proses pembakaran batu bara sehingga batu bara dengan cepat terbakar dan kayu terbakar lebih lambat.

Setiap pemasukan satu ton batubara dapat mengurangi penggunaan kayu bakar sebanyak 8 - 9 ton. Kecepatan pemasukan batubara antara 40 - 60 kg/jam. Kayu bakar juga terus ditambahkan sehingga api dari kayu dan 
batu bara berimbang dan dicapai efisiensi pembakaran yang maksimum.

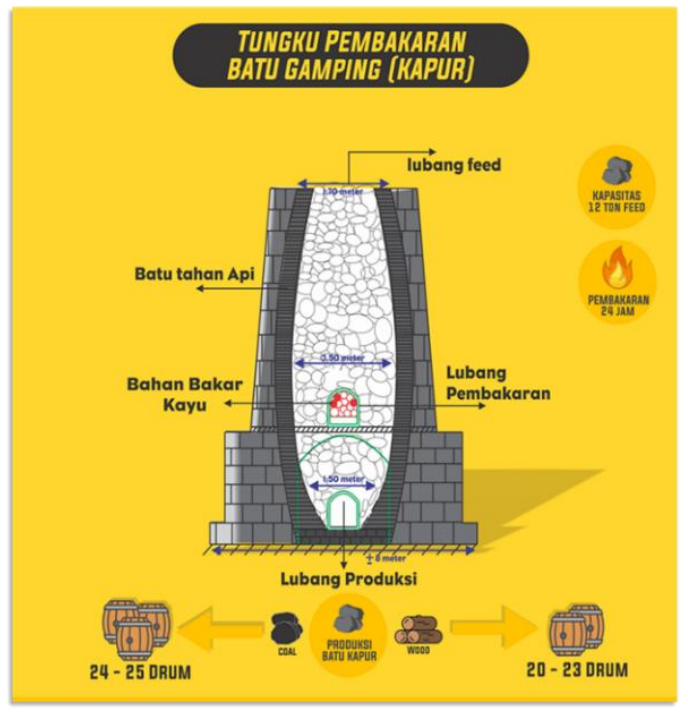

Gambar 3 Model Tungku Pembakaran Batu Kapur dengan Bahan Bakar Batubara- Kayu

\section{Tahap Pengambilan Hasil}

Hasil dari pembakaran batu kapur dengan menggunakan bahan bakar batubara - kayu ini, dapat dilihat dengan jangka waktu per 6 jam sekali dengan kisaran 25 drum dalam satu kali produksi. Tetapi, jika tidak menggunakan modifikasi batubara, maka dalam sekali produksi biasanya lebih sedikit, sekitar 20 drum, itupun masih ada bahan baku batu kapur yang masih mentah, berbeda dengan pemakaian batubara yang cenderung lebih cepat "matang" dalam hasil produksinya. Hasil pembakaran setelah dikeluarkan dari lubang produksi akan diangkut menggunakan drum menuju truk untuk selanjutnya dibawa ke tempat crushing plant, yang bertujuan untuk menghancurkan batu kapur ini

\section{Hasil Penelitian dan Pembahasan}

\section{Hasil Temperatur Batu Kapur Setelah Dibakar Dengan Menggunakan Bahan Bakar Batubara - Kayu}

Pada hasil pembakaran batu kapur dengan menggunakan bahan bakar batubara kayu didapat hasil temperaturnya sebagai berikut :

Tabel 2 Hasil Uji Temperatur Batu Kapur Dengan Bahan Bakar Batubara - Kayu

\begin{tabular}{|c|c|c|c|c|}
\hline \multirow{2}{*}{ No } & \multicolumn{2}{|c|}{ Bahan Bakar Batubara - Kayu } & \multicolumn{2}{|c|}{ Bahan Bakar Kayu } \\
\hline & Pengambilan Produksi & Suhu $\left({ }^{\circ} \mathrm{C}\right)$ & Pengambilan Produksi & Suhu $\left({ }^{\circ} \mathrm{C}\right)$ \\
\hline 1 & $\begin{array}{l}\text { Selasa, } 17 \text { Juli } 2018 \\
\text { Pukul } 09.00 \text { WIB }\end{array}$ & 94 & $\begin{array}{c}\text { Selasa, } 10 \text { Juli } 2018 \\
\text { Pukul } 09.00 \text { WIB }\end{array}$ & 85 \\
\hline 2 & $\begin{array}{c}\text { Selasa, } 17 \text { Juli } 2018 \\
\text { Pukul } 15.00 \text { WIB }\end{array}$ & 95 & $\begin{array}{c}\text { Selasa, } 10 \text { Juli } 2018 \\
\text { Pukul 15.00 WIB }\end{array}$ & 88 \\
\hline 3 & $\begin{array}{c}\text { Selasa, } 17 \text { Juli } 2018 \\
\text { Pukul } 21.00 \text { WIB }\end{array}$ & 93 & $\begin{array}{c}\text { Selasa, } 10 \text { Juli } 2018 \\
\text { Pukul } 21.00 \text { WIB }\end{array}$ & 88 \\
\hline 4 & $\begin{array}{l}\text { Rabu, } 18 \text { Juli } 2018 \\
\text { Pukul 03.00 WIB }\end{array}$ & 95 & $\begin{array}{c}\text { Rabu, } 11 \text { Juli } 2018 \\
\text { Pukul 03.00 WIB }\end{array}$ & 86 \\
\hline 5 & $\begin{array}{c}\text { Rabu, } 18 \text { Juli } 2018 \\
\text { Pukul } 09.00 \text { WIB }\end{array}$ & 94 & $\begin{array}{c}\text { Rabu, } 11 \text { Juli } 2018 \\
\text { Pukul } 09.00 \text { WIB }\end{array}$ & 87 \\
\hline 6 & $\begin{array}{l}\text { Rabu, } 18 \text { Juli } 2018 \\
\text { Pukul } 15.00 \text { WIB }\end{array}$ & 92 & $\begin{array}{c}\text { Rabu, } 11 \text { Juli } 2018 \\
\text { Pukul } 15.00 \text { WIB }\end{array}$ & 85 \\
\hline
\end{tabular}




\begin{tabular}{|c|c|c|c|c|}
\hline \multirow{2}{*}{ No } & \multicolumn{2}{|c|}{ Bahan Bakar Batubara - Kayu } & \multicolumn{2}{c|}{ Bahan Bakar Kayu } \\
\cline { 2 - 5 } & Pengambilan Produksi & Suhu $\left({ }^{\circ} \mathrm{C}\right)$ & Pengambilan Produksi & Suhu $\left({ }^{\circ} \mathrm{C}\right)$ \\
\hline 7 & $\begin{array}{c}\text { Rabu, 18 Juli 2018 } \\
\text { Pukul 21.00 WIB }\end{array}$ & 95 & $\begin{array}{c}\text { Rabu, 11 Juli 2018 } \\
\text { Pukul 21.00 WIB }\end{array}$ & 88 \\
\hline 8 & $\begin{array}{c}\text { Kamis, 19 Juli 2018 } \\
\text { Pukul 03.00 WIB }\end{array}$ & 95 & $\begin{array}{c}\text { Kamis, 12 Juli 2018 } \\
\text { Pukul 03.00 WIB }\end{array}$ & 85 \\
\hline 9 & $\begin{array}{c}\text { Kamis, 19 Juli 2018 } \\
\text { Pukul 09.00 WIB }\end{array}$ & 92 & $\begin{array}{c}\text { Kamis, 12 Juli 2018 } \\
\text { Pukul 09.00 WIB }\end{array}$ & 86 \\
\hline 10 & $\begin{array}{c}\text { Kamis, 19 Juli 2018 } \\
\text { Pukul 15.00 WIB }\end{array}$ & 94 & $\begin{array}{c}\text { Kamis, 12 Juli 2018 } \\
\text { Pukul 15.00 WIB }\end{array}$ & 86 \\
\hline 11 & $\begin{array}{c}\text { Kamis, 19 Juli 2018 } \\
\text { Pukul 21.00 WIB }\end{array}$ & 93 & $\begin{array}{c}\text { Kamis, 12 Juli 2018 } \\
\text { Pukul 21.00 WIB }\end{array}$ & 87 \\
\hline 12 & $\begin{array}{c}\text { Jum'at, 20 Juli 2018 } \\
\text { Pukul 03.00 WIB }\end{array}$ & $\begin{array}{c}\text { Suhu Rata-rata } \\
\text { Pukul 03.00 WIB }\end{array}$ & 85 \\
\hline
\end{tabular}

Data temperatur yang dihasilkan dari pembakaran menggunakan bahan bakar batubara - kayu ini didapat dengan pengujian sendiri, dengan mencampurkan antara batu kapur hasil pembakaran yang sudah melalui proses kominusi dengan ukuran 100 \# dengan campuran air, pencampuran tersebut dilakukan dengan perbandingan $1: 2$, yang dimana 100 gram batu kapur dengan 200 gram air.

Data temperatur yang dihasilkan dari pembakaran menggunakan bahan bakar kayu ini didapat dengan pengujian sendiri juga, dengan mencampurkan antara batu kapur hasil pembakaran yang bakar batubara dapat dilihat pada Tabel 3 sudah melalui proses kominusi dengan ukuran 100 \# dengan campuran air, pencampuran tersebut dilakukan dengan perbandingan $1: 2$, yang dimana 100 gram batu kapur dengan 200 gram air.

\section{Pengujian Analisis Proksimat Pada Bahan Bakar Batubara}

Pengujian analisis proksimat batubara ini dilakukan di Laboratorium Analisis Batubara Pusat Penelitian dan Pengembangan Teknologi Mineral dan Batubara (Puslitbang tekMIRA). Hasil pengujian analisis proksimat pada bahan

Tabel 3 Hasil Pengujian Analisis Proksimat Batubara

\begin{tabular}{|c|c|c|c|}
\hline \multirow{2}{*}{ Parameter Analisis } & Sample Marks & \multirow{2}{*}{ Unit } & \multirow{2}{*}{ Basis } \\
\cline { 2 - 3 } & Batubara & $\%$ & adb \\
\hline Moisture & 14,39 & $\%$ & adb \\
\hline Ash Content & 3,78 & $\%$ & adb \\
\hline Volatile Matter & 53,5 & $\%$ & adb \\
\hline Fixed Carbon & 38,55 & $\%$ & \\
\hline
\end{tabular}

Sumber : Data PKM 2018 


\section{Pengujian Batu Gamping di Laboratorium}

Pengujian analisis Proksimat batubara ini dilakukan di Laboratorium Analisis Batubara Pusat Penelitian dan Pengembangan Teknologi Mineral dan Batubara (Puslitbang teMIRA). Hasil pengujian unsur pada batu kapur hasil pembakaran, dapat dilihat pada Tabel 4.

Tabel 4 Hasil Pengujian Batu Gamping

\begin{tabular}{|lc|c|c|}
\hline Nomor Lab. & $4119 / 18$ & \multirow{2}{*}{ Metode } \\
\cline { 1 - 2 } Kode Contoh & & Batu Kapur & ASTM C25-11 \\
\hline CaO total & $\%$ & 75,67 & Volumetri \\
\hline CaO bebas & $\%$ & 67,94 & ASTM C25-11 \\
\hline $\mathrm{CaCO}_{3}$ & $\%$ & 13,79 & ASTM C25-11 \\
\hline LOI & $\%$ & 22,15 & ASTM C 1301-95 (Reap 2014) \\
\hline MgO & $\%$ & 1,13 & \\
\hline
\end{tabular}

Sumber : Data PKM 2018

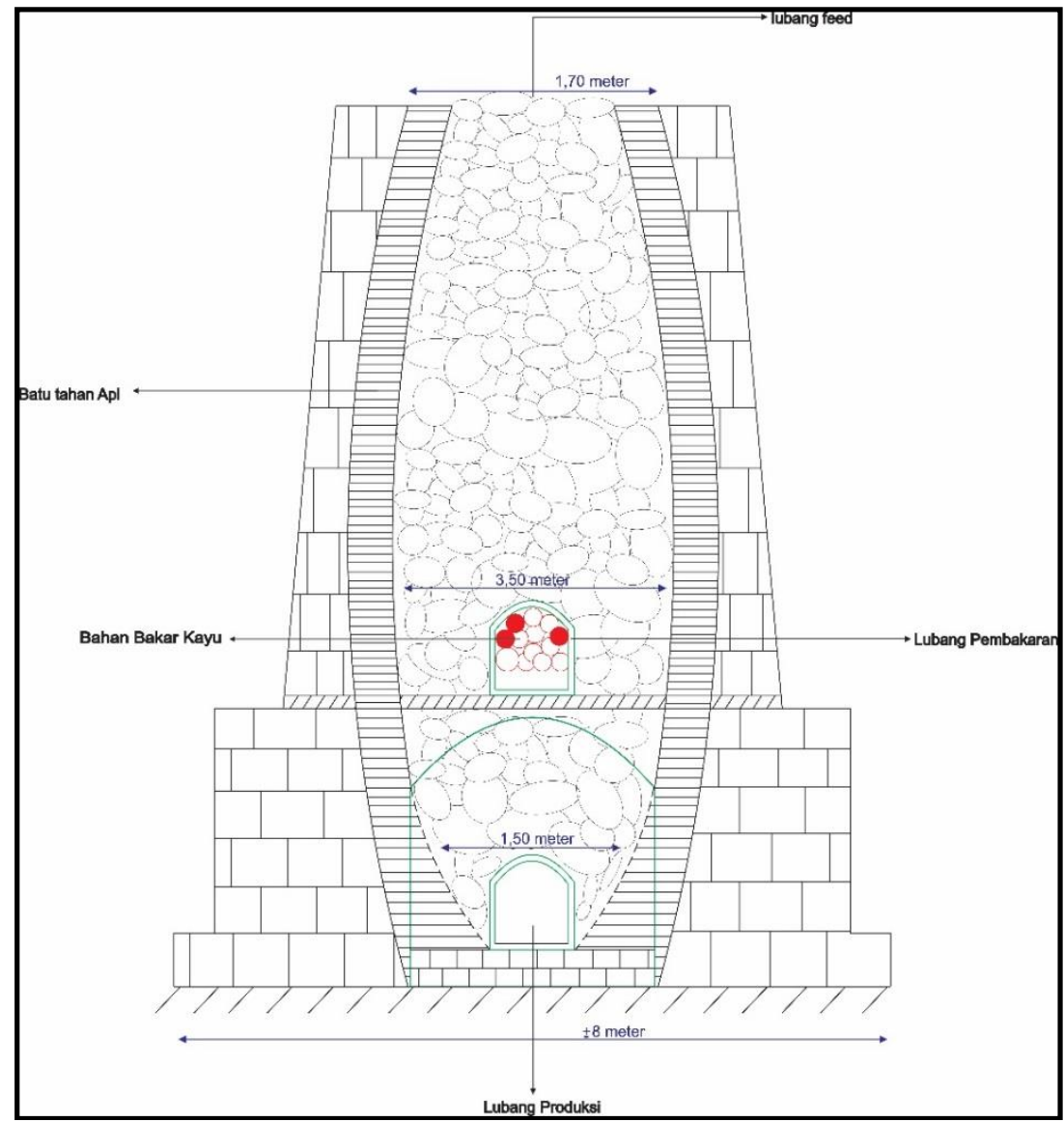

Gambar 4 Sketsa Tungku Pembakaran 


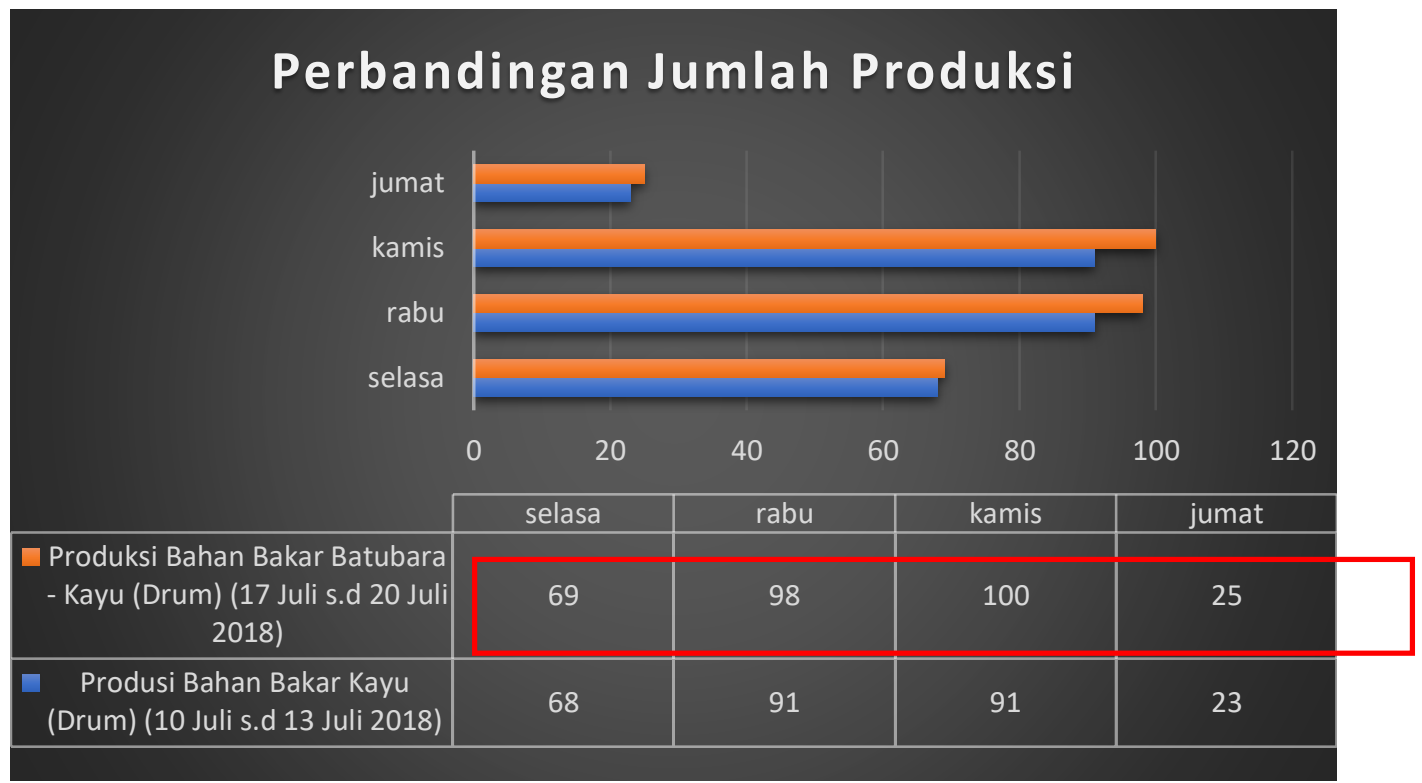

Gambar 5 Grafik Perbandingan Produksi Antara Bahan Bakar Batubara - Kayu

Dengan Bahan Bakar Kayu

Dari hasil grafik diatas, dapat diketahui bahwa jumlah produksi dengan menggunakan dua jenis bahan bakar yang berbeda terdapat perbedaan yang cukup signifikan, hal tersebut dapat terjadi karena perbedaan bahan bakar yang digunakan.

Jika dilihat dari hasil grafik diatas, dalam hal jumlah produksi, menunjukkan bahwa penggunakan bahan bakar dengan modifikasi batubara - kayu jauh lebih efisiensi dibandingkan dengan bahan bakar kayu saja, perbedaannya pun lumayan sangat besar sekitar 8-9 drum dalam pengambilan produksi selama 24 jam. Hal ini dapat terjadi karena bahan bakar yang digunakan menggunakan 2 jenis bahan bakar, dan tentunya dengan penambahan bahan bakar batubara ini dapat menambah panas dari pembakaran batu kapurnya itu sendiri.
Dengan jumlah produksi yang lebih banyak dari biasanya ini tentunya akan lebih cepat dalam proses mobilisasi menuju laboratorium dalam uji temperaturnya, jika rata - rata produksi dengan menggunakan bahan bakar batubara - kayu sebanyak \pm 100 drum atau sekitar 10 ton dalam waktu 24 jam, dengan kapasitas muat truknya \pm 10 ton juga, maka dalam setiap 24 jam truk tersebut dapat terus memproduksi hasil pembakaran batu kapur dengan muatan yang maksimal. Tetapi jika rata - rata produksi hanya dengan menggunakan bahan bakar kayu sebanyak \pm 90 drum atau sekitar 9 ton dalam waktu 24 jam, dengan kapasitas muat truk yang sama, maka, jika pengangkutan dilakukan setiap 24 jam, kapasitas muatan truk tersebut tidak akan maksimal. 


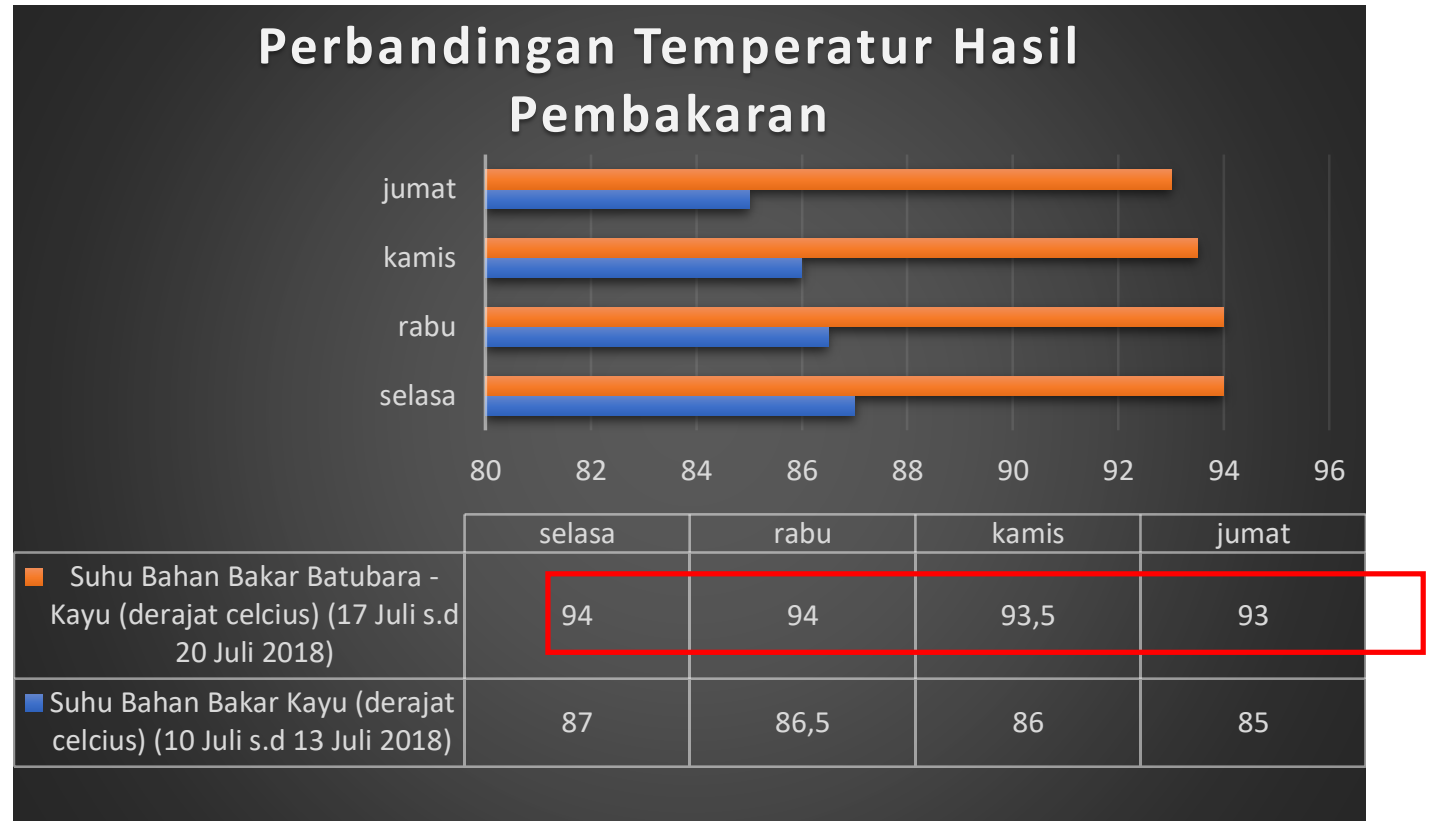

Gambar 6. Grafik Perbandingan Temperatur Antara Bahan Bakar Batubara - Kayu Dengan Bahan Bakar Kayu

Data grafik diatas merupakan data hasil akumulasi rata -rata suhu pada setiap 24 jam pengambilan produksi. Berdasarkan hasil data yang didapat dari grafik diatas, dapat terlihat perbedaan yang sangat mencolok, dimana rata rata suhu yang dihasilkan pada hasil pembakaran batu kapur dengan mengunakan bahan bakar batubara kayu ini jauh berbeda dengan hasil pembakaran menggunakan bahan bakar kayu saja. Perbedaan range yang sangat jauh ini sekitar $5-6{ }^{\circ} \mathrm{C}$ lebih panas menggunakan bahan bakar modifikasi batubara - kayu, dan hasil yang didapat ini sangat mempengaruhi terhadap kualitas dari batu kapurnya itu sendiri, apakah batu kapur tersebut termasuk kedalam klasifikasi lembab, kering lembab, atau bahkan kering.

Pengklasifikasian batu gamping hasil pembakaran terdapat 3 klasifikasi, yaitu :

Tabel 5 Pengklasifikasian Hasil Pembakaran Batu Kapur

\begin{tabular}{|c|c|c|}
\hline NO & Klasifikasi & Range Suhu $\left({ }^{\circ} \mathrm{C}\right)$ \\
\hline 1. & Lembab & $80-85$ \\
\hline 2. & Kering Lembab & $86-90$ \\
\hline 3. & Kering & $>91$ \\
\hline
\end{tabular}

Jika dilihat dari tabel diatas, dan juga dilihat dari hasil pembakarannya, hasil pembakaran batu kapur dengan menggunakan bahan bakar batubara kayu ini termasuk kedalam klasifikasi kering, dengan klasifikasi kering ini, kualitas produk dari batu kapur ini akan memiliki nilai jual yang cukup tinggi, berbeda halnya jika hanya menggunakan bahan bakar kayu saja, dari hasil data yang didapat, hasil pembakaran denan menggunakan bahan bakar kayu saja hanya memiliki suhu sekitar $85-87^{\circ} \mathrm{C}$, dan ini masuk klasifikasi kering lembab yang mengakibatkan kualitas pada hasil pembakarannya tidak maksimal dan harga jual nya pun aka lebih rendah 
dibandingkan dengan hasil pembakaran bahan bakar batubara - kayu.

\section{Kesimpulan Dan Saran}

\section{Kesimpulan}

Berdasarkan kegiatan penelitian yang telah dilakukan, maka dapat diambil kesimpulan yaitu pemahaman adanya bahan bakar batubara sebagai bahan bakar pembakaran batu kapur sudah dipahami sebagian pekerja di pabrik kapur Sinar Sakti, tetapi karena ketersediaan bahan bakar kayu dan limbah lainnya dari pemasok lebih terjamin serta harga yang lebih murah menyebabkan limbah kayu dan limbah lainnya masih tetap digunakan sebagai bahan bakar. Pembakaran batu kapur saat ini menggunakan bahan bakar kayu, limbah ban dan limbah kulit menghasilkan batu kapur dengan keadaan kering lembab dengan suhu pembakaran rata-rata $86,33{ }^{\circ} \mathrm{C}$ atau masih mengandung kadar air. Dari hasil penerapan pembakaran batu kapur pada tungku tegak sistem berkala dengan menggunakan bahan bakar campuran batubara dan kayu dengan umpan 12 ton batu kapur mentah (raw) menghasilkan batu kapur kering dengan suhu pembakaran rata-rata $93,75{ }^{\circ} \mathrm{C}$ sebanyak 2,75 ton (setara 25 drum). Hasil pembakaran ini lebih banyak dibandingkan pembakaran batu kapur dengan bahan bakar kayu dan limbah.

\section{Saran}

Adapun saran yang dapat penulis berikan kepada semua pihak yang terlibat dalam penelitian artikel ini, di antaranya yaitu ukuran batu kapur yang masuk kedalam tungku pembakaran hendaknya berukuran $20-30 \mathrm{~cm}$, agar pembakaran pada batu kapur cepat menembus inti dari batu kapurnya sehingga mempercepat tingkat kematangan dari batu kapur.Dengan hasil pembakaran menggunakan bahan bakar batubara - kayu, seharusnya waktu pengeluaran produksi bisa lebih cepat dari biasanya, tidak selalu harus per 6 jam sekali.Penerapan pemakaian batubara sebagai bahan bakar pembakaran batu kapur dengan tungku tegak system berkala perlu dikaji keekonomisan untuk penerapan teknologi ini selanjutnya.

\section{DAFTAR PUSTAKA}

Moropoulou, Antonio, Asteios Bakolas and Eleni Aggelakopoulou. (2001). "TheEffects of Limestone Characteristics and Calcination Temperature to The Reactivity of The Quicklime.", Cement and Concrete Research, 31: 633-639.

Senegačnik, Andrej, Janez Oman dan Brane Širok.(2007), "Analysis of Calcination Parameter and The Temperature Profile in An Annular Shaft Kiln. Part 1", Theoretical Survey. Applied Thermal Engineering, 27: 146-14 